ve must take care that we do not excite inflammation of the ovaries, or of the womb. When we find the patient complaining of severe pain in the loins, and suffering from general fever, we ought at once to discontinue mammary irritation, and prescribe rest in bed, abdominal fomentations, and the frequent use of the hip-bath. In cases of this description, as in ordinary attacks of dysmennorrhœa, we may often not only relieve pain, but accelerate a resolution of the inflammation, by administering opiate enemata.

Caution on the part of the practitioner will generally enable him to prevent or speedily remove the evils and inconveniences to which reference has been made. They may, however, so easily occur through the want of it, and lead to ho much discredit and embarrassment, that I have been anxious to give them the prominence which they deserve.

Fssex House, Putney, 10th March, 1s.50.

\section{ON DISTICHIASIS.}

Dy HAYNES WV.ALTON, Fisq., F.R.C.S., Surgenn to the Central London Ophthalmic: Hospital, Assistant-Surgeon to St. Mary's Hospital, ete.

Distrchiasis having been lately brought before the members of the Association through the medium of our Jou RNAL, I am desirous to record my own views respecting that condition of the eyclashes which this term is meant to imply.

Distichiasis, from 8is, twice, and orixos, a row (one of the many pedantic words that yet obscure the writings devoted to diseases of the eye), is usually employed to signify that a second, or supplemental, row of cilia or eyelashes exists ; but the correctness of this, as a pathological state, I disputc. The matter is not devoid of practical interest, and this I purpose to show in a subsequent communication on the treatment of certain affections of the eyelids.

I maintain that the supposed new row consists of the natural cilia merely displaced; and that the idea of superadded eyelashes is an error, which arises out of the normal yet irregular disposition of the nanner in which they are set on the lid, and which becomes very apparent when the inwards and away from those which are most external. The deception is still greater, when abortive cilia supplant those along the inner margin of the eyelid, and grow without any curve, but straight, and incline rather towards the eyeball than in any other direction. I have observed examples of abortive eyelashes growing inwards, nearly at a right angle to the tarsal cartilage. Of the truth of the assertion of the irregular disposition alluded to, any one may convince himself by selecting for experiment a healthy eyelid, separating the most internal of the eyclashes with a probe, and producing the so-called distichiasis, This is, in fact, what is done by disease, and is effected in threc ways -by the agglutination of some of the cilia with lachrymal secretions, in certain affections of the conjunctiva, or of the Meibomian glands, in consequence of which they are turned against the eycball; by long-continued malposition in inversion of the eyelid; and, most frequently of all, by disease of the edge of the eyelid, producing pathological changes in the dense fibro-cellular tissue that surrounds the hair follicles, and perbaps also by changes in the follicles themselves. A case, remarkably illustrative of the last clause, came under my notice at the Central London Ophthalmic Hospital. A lad was brought there with chronic inflammation of the upper eyelid. of three years' duration, by which the edge of the lid was considerably thickened, and the eyelashes separated into two distinct rows. Several months afterwards, when all traces of preternatural vascularity had ceased, and the eyelid had nearly recovered its natural size, the duplex arrangement of the cilia was no longer apparent.

So far as I am aware, there are not any physiological facts that at all support the theory of hair being developed after foctal life; that is, there is not on the surface of the body any secondary formation of hair follicles, these being of primary existence. The appearance of hair on parts apparently devoid of it, after the application of blisters, or the accession of increased vascular action, has been often advanced in proof of the secondary creation; but this argument is quite demolished by the fact that the entire surface of the body, with the exception of the palms of the hands and the soles of the feet, is thickly set with hair follicles; and by the deduction from this fact, that when hair is so accidentally developed, the phenomenon must be ascribed to hyper-nutrition of normal germs.

Those who contend for the existence of distichiasis, but cannot overcome the fact of there being no secondary creation of hair, declare that the irregular eyelashes, although proceeding from old hair follicles, perforate the lid more internally than natural. This cannot be, unless the hair pass through the tarsal cartilage (a supposition that is manifestly absurd) ; for the most internal of the eyelashes, as every one who has dissected the eyelids minutely, as every one who as it is possible by the side of the cartilage.

In the Dublin Quarterly Journal of Medical Science for February 1853, the revicwer of my treatise on "Operative Ophthalmic Surgery", makes the following remarks on this question:- "It has always appeared to us surprising, that question:- - It has one could imaginc this extraordinary growth, how it could be, or why it should be produced. We have examined a very large number of persons affected with the disease under consideration, and could not, in any case, discover the extra number of cilia, comparing the diseased with a sound cye in the same person-the only possible way, we maintain, by which a fair and correct opinion can be formed; for it is obvious that, if we were to compare the number of cilia to be found in the lids of one suffering from the complaint, with those in sound eyelids in another person, we would be proceeding upon very irregular principles, were we to found any argument upon such data."

69, Brook Strect, Hunover Square, March $185 \check{3}$.

\section{REMARKS ON A NEW KIND OF CATHETER, MADE OF VULCANIZED INDIA-RUBBER.}

\section{By W. VINER BEADLE, M.D.}

Findina, in a case some time since under my care, that the ordinary catheters produced or kept up irritation of the mucous membrane of the bladder, and produced also great general disturbance, I was induced to try a catheter made of vulcanized India-rubber.

C.ASE. Mr. H., aged 80, had at different times suffered from incomplete retention of urine; but the attacks bad always hitherto passed off without instrumental assistance. In this attack, after exposure to cold, he had felt colicky pains in the umbilical region, combined with slight diarrhoce. He had constant calls to micturition, though unable to pass more than a small quantity at a time, and that in drops. In a day or two, the retention becoming urgent, and the pain sevcre, although urine was still passed, he applied for assistance. The bladder, having become more distended, had in the same ratio lost more of its contractile power, and no longer possessed the power of lessening its cavity, or expelling the contents. Such was the state in which I first saw him, on the 16th of July. Being five or six miles from my residence, and unable to return that night with instruments, I prescribed fomentations and an anodyne. These measures afforded little relief.

July 17th. Early this morning, I used the catheter, drawing off a good deal of urine, of a dark colour, and which, on cooling, showed a considerable deposit of mucus. The catheter passed easily ; and the prostate, though tender, did not seem greatly enlarged. I prescribed the following pills to be taken at bed-time, and an aperient draught in the morning :-

B. I'ilula hydrargyri,

Pilula saponis comp. àa gr. v. Ft. pil. ij.

July 18th. The urine was drawn off. It was still dark, 